\title{
Distribution and Habitat Preference of Red Panda (Ailurus fulgens fulgens) in Jumla District, Nepal
}

\author{
Manoj Bhatta1, Karan Bahadur Shah'², Bhupendra Devkota ${ }^{3}$, Rajiv Paudel ${ }^{4}$, Saroj Panthi5* \\ ${ }^{1}$ Amrit Science Campus, Kathmandu, Nepal \\ ${ }^{2}$ Natural History Museum, Tribhuvan University, Kathmandu, Nepal \\ ${ }^{3}$ College of Applied Science, Kathmandu, Nepal \\ ${ }^{4}$ Winrock International, Lalitpur, Nepal \\ ${ }^{5}$ Department of Forests, District Forest Office, Darchula, Nepal \\ Email: manojenvbhatta@gmail.com, ${ }^{*}$ mountsaroj@gmail.com
}

Received 18 September 2014; revised 19 October 2014; accepted 4 November 2014

Copyright (C) 2014 by authors and Scientific Research Publishing Inc.

This work is licensed under the Creative Commons Attribution International License (CC BY). http://creativecommons.org/licenses/by/4.0/

(C) (i) Open Access

\section{Abstract}

Reliable and sufficient information regarding status, distribution and habitat preference of red panda (Ailurus fulgens fulgens) is lacking in Nepal. The research activities on red panda in the mid-western Nepal are very limited, so the status of red panda in the region is quite unknown. The study conducted during May, 2013 in three Village Development Committees (VDCs) namely Godhemahadev, Malikathata and Tamti of Jumla district was an important step for providing vital information including distribution and habitat preference of this species. The study included the reconnaissance, key informants survey, interviews and consultation for the most potential area identification, opportunistic survey comprising the direct observation and indirect sign count method for the presence and distribution, habitat assessment consisting vegetation sampling and ocular estimation. The study revealed the presence of red panda in three forests namely Bahirepatan, Imilchadamar and Tyakot of Godhemahadev, Tamti and Malikathata VDCs respectively. The species was found distributed between 2880 and $3244 \mathrm{~m}$ with an average dropping encounter rate of 1.04 per hour of searching effort and 12 pellets per dropping. Red panda mostly preferred the habitat in the elevation range of $2900-3000 \mathrm{~m}$ with southwest facing steep slopes $\left(36^{\circ}-45^{\circ}\right)$, associated with water sources at the distance of $\leq 100 \mathrm{~m}$. Trees such as Acer spp., Betula utilis and Quercus semecarpifolia, shrub species of Elaeagnus parvifolia, Drepanostachyum spp. and Jasminum humile, and the herbs like Polygonatum cirrhifolium, Fragaria nubicola and Galium asperifolium were found to be the most preferred species by red panda. The red panda preferred the habitat with dense crown coverage $(>20 \%-100 \%)$ and $31 \%-50 \%$ ground cover. Fallen logs $(39 \%)$ were the most preferred substrate used for defecation.

\footnotetext{
${ }^{*}$ Corresponding author.
}

How to cite this paper: Bhatta, M., Shah, K.B., Devkota, B., Paudel, R. and Panthi, S. (2014) Distribution and Habitat Preference of Red Panda (Ailurus fulgens fulgens) in Jumla District, Nepal. Open Journal of Ecology, 4, 989-1001. 


\section{Keywords}

Distribution, Habitat Preference, Jumla, Red Panda, Sign

\section{Introduction}

The red panda (Ailurus fulgens), the sole representative species of the monotypic family Ailuridae, one among the two sub-species Ailurus fulgens fulgens and Ailurus fulgens styani [1] [2], is a threatened carnivore mammal species.

Globally, red pandas are found throughout the Himalayan mountains of Nepal, India, Bhutan, Myanmar and China between 2200 and $4800 \mathrm{~m}$ altitude [1]-[8]. The habitat of red pandas is associated with the occurrence of subtropical and temperate forests with an exceptional case in tropical forest of Meghalaya in India [6].

In Nepal, red pandas are distributed within a narrow elevation range between 2500 and $4200 \mathrm{~m}$ in the northern part of the country and are confirmed to occur in eight Protected Areas (PAs) including Langtang National Park and Buffer Zone (LNP and BZ) [9]-[11], Kangchenjungha Conservation Area (KCA) [12], Makalu Barun National Park and Buffer Zone (MBNP and BZ) [13], Sagarmatha National Park and Buffer Zone (SNP and BZ) [14], Annapurna Conservation Area (ACA) [13], Dhorpatan Hunting Reserve (DHR) [15]-[18], Rara National Park and Buffer Zone (RNP and BZ) [19] and Gaurishankar Conservation Area (GCA) [20]. Beside this, some of the studies suggested the presence of red panda outside the PAs in Nepal. The evidences of its presence have been documented in the forest patches of Illam [21] [22], Panchthar and Taplejung [22], and Sankhuwasabha [23] districts in the eastern Nepal. Its presence has also been recorded in Manang district, north-central part of Nepal [24] and Kalikot [25], Jajarkot [26] of mid-western Nepal.

\section{Materials and Methods}

\subsection{Study Area}

Jumla district is situated in Karnali zone of the mid-western development region with total area, $2531 \mathrm{~km}^{2}$. The district is surrounded by Dolpa district in the east, Kalikot district in the west, Mugu district in the north and Jajarkot district in the south (Figure 1). Jumla Khalanga is the district headquarters of Jumla district. The entire

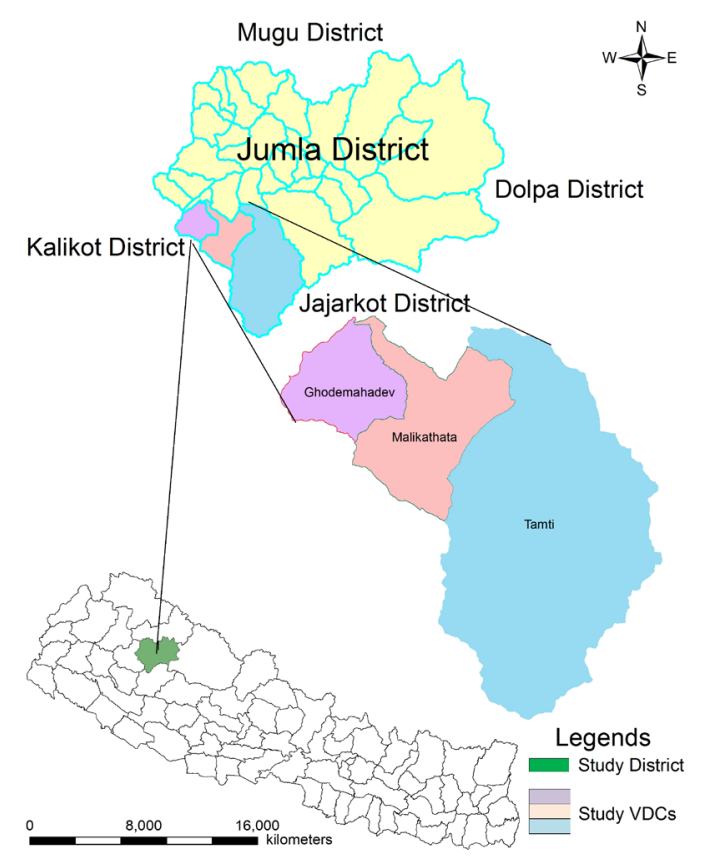

Figure 1. Location map of the study area. 
district is divided into nine forest Illakas, and 30 Village Development Committees (VDCs). The district can be accessed either through Surkhet-Jumla Karnali Public Highway $(232 \mathrm{~km})$ or via air service from Surkhet and Nepalgunj [27].

Three VDCs namely Godhemahadev, Malikathata and Tamti were selected for the study purpose and the detail study has been carried out in the Bahirepatan, Tyakot and Imilchadamar forests of Godhemahadev, Malikathata and Tamti VDCs respectively.

\subsection{Distribution}

We conducted the reconnaissance including the interaction with various representative offices as the key informants comprising the District Forest Office (DFO), ranger posts, District Development Committee (DDC), and VDCs. Similarly, interactions with villagers, herders, village level conservation committee through consultation meeting and focused group discussions regarding presence and distribution of red panda further helped for the exploration and identification of the potential habitats of red panda in the study area. Meanwhile, pamphlets and photographs of red panda, their pellets, habitats, and their preferred foods were displayed during the reconnaissance. For getting representative and reliable information, opportunistic sampling strategy was adopted for the survey. Both direct and indirect methods of wildlife survey were applied in the field. However, indirect sign count method was significant throughout the study period. We have collected geo-referenced with hand-held Geological Positioning System (GPS) unit wherever we observed the direct and indirect signs of the species and Arc Geographical Information System (GIS) and Google earth were used to prepare distribution map.

\subsection{Habitat Preference}

Ivlev's electivity index (IV) was used to analyze the habitat preference of red panda which includes various habitat parameters such as vegetation, slope, elevation, aspect, vegetation composition, cover and distance from nearest water sources. In addition, the value of index ranges from -1.0 to +1.0 where positive values implies preference, negative values refers avoidance and 0 values indicates random use. The formula developed by Ivlev [28] and followed by Yonzon and Hunter [29], Panthi et al. [17] was used to calculate the habitat preference of red panda, which can be expressed as $I V=(U \%-A \%) /(U \%+A \%)$, where "A" indicates "availability plots" and " $U$ " infers "use plots".

Vegetation in any area indicates the habitat suitability and preference for the particular species that is core component for the habitat specialist like red panda. The detail vegetation analysis was carried out to determine the floral composition of the habitat. Quadrates of size $10 \mathrm{~m} \times 10 \mathrm{~m}$ for tree layer (plant above $3 \mathrm{~m}$ height and 5 $\mathrm{cm} \mathrm{DBH}$ ), $4 \mathrm{~m} \times 4 \mathrm{~m}$ for shrubs layer (woody plant below $3 \mathrm{~m}$ in height) and $1 \mathrm{~m} \times 1 \mathrm{~m}$ for herbs layer (plants up to $1 \mathrm{~m}$ in height) were used in both habitat use plot $(U)$ and habitat availability plots $(A)$. The quadrates sizes were determined as suggested by Cottam [30]. In each plot, number of trees, shrubs and herbs, their frequency and ground coverage were determined on the basis of ocular estimation. In addition, DBH, height and canopy coverage of trees were also recorded. The unidentified plant species were collected and taken to national herbarium and plant laboratories, Godawari, Lalitpur, Nepal, for identification and further authentication.

\section{Results}

\subsection{Red Panda Distribution in the Study Area}

Presence of red panda (locally known as "Nautoto") was confirmed in three VDCs (Godhemahadev, Malikathata and Tamti) of Jumla district. Red panda signs (pellets) were observed in Bahirepatan, Tyakot and Imilchadamar forests of those three respective VDCs (Figure 2).

On $21^{\text {st }}$ May 2013 (9:30 a.m.), one adult red panda was sighted in Tyakot forests of ward No. 9, Khopry, Malikathata VDC. The observed site $\left(29^{\circ} 08^{\prime} 36.7^{\prime \prime} \mathrm{N}, 82^{\circ} 02^{\prime} 04.0^{\prime \prime} \mathrm{E} ; 2894 \mathrm{~m}\right)$ was at southwest facing slope with $41^{\circ}$ slope and at about $100 \mathrm{~m}$ from the nearest water source. The red panda observed at a distance of approximately $50 \mathrm{~m}$ was defecating at its latrine site, where freshest pellet group (about a minute after defecation) was seen above the old pellet layer. The red panda got disturbed due to presence of the observers and suddenly escaped from the site and disappeared in the bushes. The site was dominated by Abies spectabilis with Drepanostachyum falcatum understory.

Occasionally red pandas were also observed by local resident and herders in Dugurnedando, Chilaunepani and 


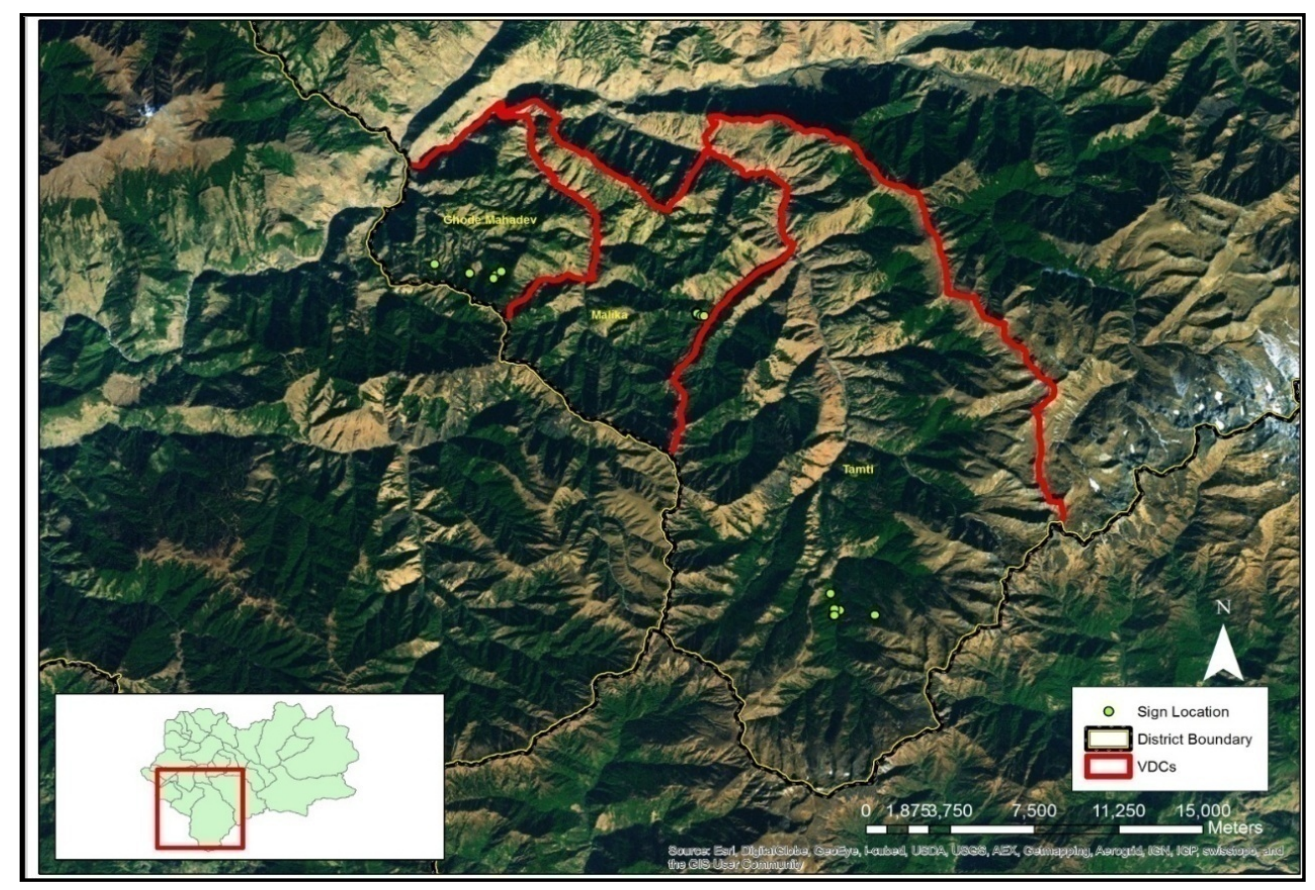

Figure 2. Distribution of red panda in the study area.

Chada forest areas of Ghodemahadev VDC, Tyakot forest of Malikathata VDC and Imilchadamar forest of Tamti VDC. These forests are dominated by Abies spectabilis, Quercus semecarpifolia and Picea smithiana and bamboo understory.

Red panda's droppings were found between 2880 and $3244 \mathrm{~m}$ altitude in the study area. Out of 28 pellet groups, $50 \%$ of them were recorded in the Tyakot forest of Malikathata VDC followed by $28.57 \%$ in Imilchadamar of Tamti and 21.43\% in Bahirepatan of Godhemahadev. The red panda defecated at a particular site considered as latrine site, consisting of two or more droppings (pellets group) above the older one, however, the single dropping encountered in a plot was considered as the defecation site. In the studied plots, percentage of defecation site (85.71\%) was higher than that of latrine site (14.29\%). Single defecation site consisted of 7 to 18 pellets. However, average number of pellets per dropping in defecation site was 12 . The number of pellets in the latrine sites could not be counted, due to higher number of broken and decayed pellets. Furthermore, an encounter rate of pellet group/hour searching effort was used as an index in order to quantify the abundance in the study area. The average droppings encounter rate in the studied forests was found to be 1.04 per hour of walk (searching effort), including highest in Tyakot forest of Malikathata VDC (1.56/hour searching effort) followed by Imilachdamar of Tamti VDC (0.89/hour searching effort) and Bahirepatan of Godhemahave VDC (0.67/hour of searching effort).

\subsection{Habitat Preference by Red Panda}

\subsubsection{Elevation}

Evidences of red panda's presence were observed between $2800 \mathrm{~m}$ and $3300 \mathrm{~m}$ elevation. Red panda highly preferred the altitudinal range of $2900-3000 \mathrm{~m}(\mathrm{IV}=0.20)$, moderately preferred the elevation of $3000-3100$ $\mathrm{m}(\mathrm{IV}=0.17)$ followed by $3100-3200 \mathrm{~m}(\mathrm{IV}=0.14)$ and $2800-2900 \mathrm{~m}(\mathrm{IV}=0.09)$ and randomly used the altitude of $3200-3300 \mathrm{~m}$. Red panda completely avoided the area below $2800 \mathrm{~m}$ and above $3300 \mathrm{~m}$ altitude with $\mathrm{IV}=-1.00$ each (Figure 3).

\subsubsection{Slope}

Slope of the red panda habitat was classified according to slope category provided by Anbalagan and Singh [31]. Red panda signs (pellets) were observed between the slope of $15^{\circ}$ and $56^{\circ}$. Red panda mostly preferred steep slope (IV $=0.14,37.50 \%$ ), moderately preferred escarpment/cliff (IV $=0.06,30.36 \%$ ), randomly used moderate 


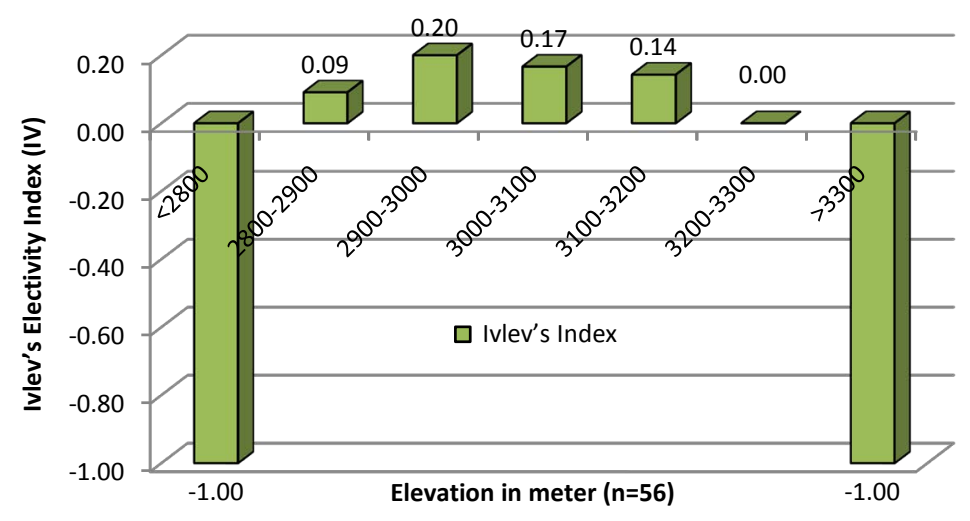

Figure 3. Elevation preference by red panda.

slope (IV $=0.00,21.43 \%)$ and avoided the gentle slope (IV $=-0.05,7.14 \%)$. However, red panda completely avoided very gentle slope (3.57\%) (Figure 4).

\subsubsection{Aspect}

Red panda mostly preferred southwest facing slopes (IV $=0.12,44.64 \%$ ), moderately preferred northwest facing slopes (IV $=0.07,26.79 \%$ ), and randomly used northeast facing slopes (IV $=0.00,14.29 \%$ ). However, red panda avoided Southeast facing slopes (IV $=-0.50,14.29 \%$ ) in the area (Figure 5).

\subsubsection{Water Source}

Red panda signs were found at the distance of $5 \mathrm{~m}$ to $350 \mathrm{~m}$ far from the nearest water sources in the study area. The species mostly preferred the distance $\leq 100 \mathrm{~m}(\mathrm{IV}=0.13)$ from the water sources followed by distance (101 200) $\mathrm{m}(\mathrm{IV}=-0.08)$ whereas, it avoided the distance greater than $200 \mathrm{~m}(\mathrm{IV}=-0.45)$, from nearest water sources (Figure 6).

\subsubsection{Substrate}

The different substrates used by red panda for defecation were fallen logs, ground (forest floor), uprooted trees and rock cliffs. Fallen logs were mostly preferred for defecation (39\%) followed by forest floor (25\%), uprooted trees (25\%) and rock cliffs (11\%) (Figure 7).

\subsubsection{Floristic Preference}

\section{1) Trees}

Tree species were examined in 56 plots (28 habitat use plots and 28 habitat availability plots) each $10 \mathrm{~m} \times 10$ $\mathrm{m}$ in size. Out of nine tree species recorded, red panda showed higher preference to Acer spp. (IVI = 27.14; IV = 0.35) followed by Betula utilis (IVI = 26.91; IV = 0.24) and Quercus semecarpifolia (IVI = 55.29; IV = 0.13). Abies spectabilis (IVI $=54.85$; IV $=0.00$ ) was randomly used whereas Tsuga dumosa, Juglans regia, Picea smithiana and Pinus wallichiana were avoided by red panda (Table 1).

2) Shrubs

Shrubs were examined in 56 plots (28 habitat use plots and 28 habitat availability plots) each of $4 \mathrm{~m} \times 4 \mathrm{~m}$ area. A total of 19 shrub species found in the red panda habitat, eight species were preferred, two species were randomly used and remaining were avoided by red panda. Red panda highly preferred Elaeagnus parvifolia (IV = 0.40) followed by Drepanostachyum falcatum (IV $=0.10$ ), Drepanostachyum intermedium $(\mathrm{IV}=0.06$ ) and Drepanostachyum Khasianum (IV $=0.04$ ) whereas Ribes himalense $(\mathrm{IV}=0.00)$ and Viburnum cotinifolium $(\mathrm{IV}=$ 0.00 ) were randomly used. However, shrubs like Coriaria nepalensi (IV $=-1.00)$, Prinsepia utilis (IV $=-0.42)$, Salix denticulate (IV $=-0.41$ ) and Rosa macrophylla (IV $=-0.37$ ) were highly avoided (Table 2).

3) Herbs

Herbaceous plants were observed in 56 plots (28 habitat use plots and 28 habitat availability plots) each $1 \mathrm{~m} \times$ $1 \mathrm{~m}$ in area. A total of 17 herbaceous plants were observed in these plots, eight of them were preferred by red panda. Polygonatum cirrhifolium (IV $=0.32$ ) was most preferred species followed by Fragaria nubicola $(\mathrm{IV}=$ 


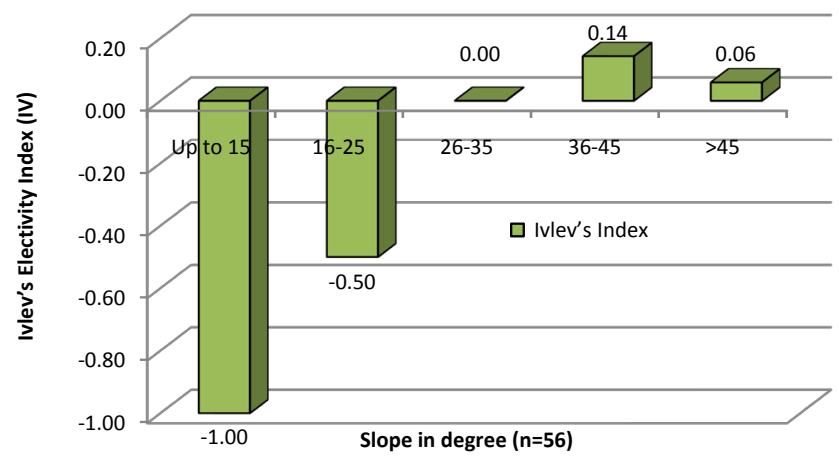

Figure 4. Slope preference by red panda.

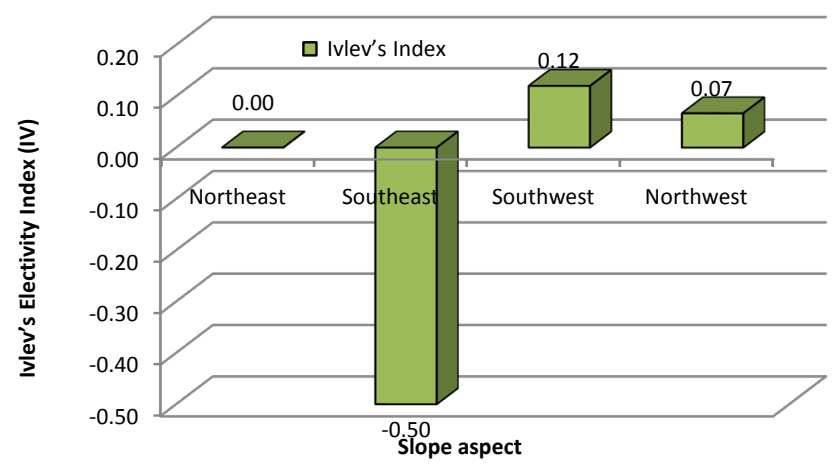

Figure 5. Aspect preference by red panda.

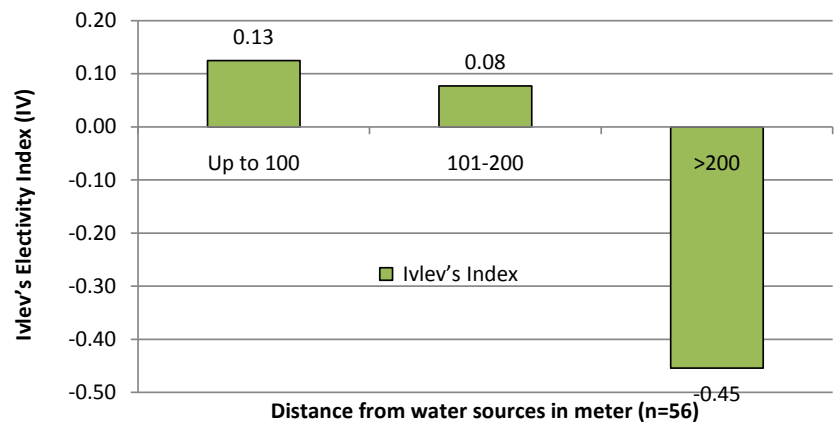

Figure 6. Preference of distance from water sources by red panda.

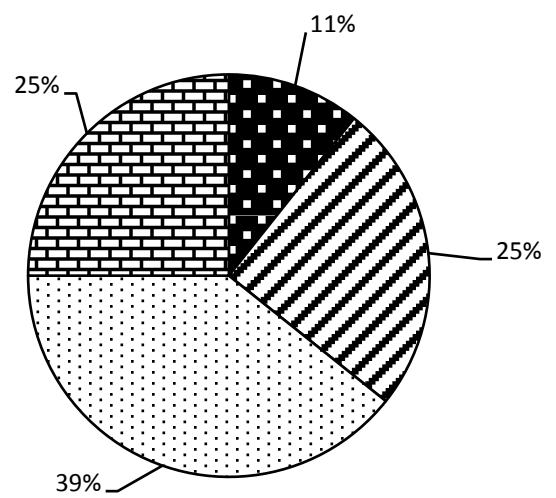

Rock cliff

चGround (forest floor)

๑Fallen log

GUprooted tree

Figure 7. Percentage of substrate used by red panda for defecation $(n=28)$. 
Table 1. Tree species according to preference by red panda.

\begin{tabular}{|c|c|c|c|c|c|c|}
\hline S.N. & Scientific name & Family & Local name & IVI & IV & Status \\
\hline 1 & Acer spp. & Aceraceae & Paalau & 27.14 & 0.35 & Preferred \\
\hline 2 & Betula utilis & Betulaceae & Bhuje & 26.91 & 0.24 & Preferred \\
\hline 3 & Quercus semecarpifolia & Fagaceae & Khasru & 55.29 & 0.13 & Preferred \\
\hline 4 & Abies spectabilis & Pinaceae & Gobrya & 54.85 & 0 & Randomly Used \\
\hline 5 & Pinus wallichiana & Pinaceae & Piu Sallo & 30.64 & -0.17 & Avoided \\
\hline 6 & Picea smithiana & Pinaceae & Jhulya & 35.8 & -0.21 & Avoided \\
\hline 7 & Rhododendron arboreum & Ericaceae & Guraunsh & 17.26 & -0.27 & Avoided \\
\hline 8 & Juglans regia & Juglandaceae & Oakhar & 23.28 & -0.4 & Avoided \\
\hline 9 & Tsuga dumosa & Pinaceae & Thigo & 28.84 & -0.52 & Avoided \\
\hline
\end{tabular}

Table 2. Shrub species according to preference by red panda.

\begin{tabular}{|c|c|c|c|c|c|}
\hline S.N. & Scientific name & Family & Local name & IV & Status \\
\hline 1 & Elaeagnus parvifolia & Elaeagnaceae & Gunyalo & 0.4 & Preferred \\
\hline 2 & Drepanostachyum falcatum & Poaceae & Malingo & 0.1 & Preferred \\
\hline 3 & Drepanostachyum intermedium & Poaceae & Jurmutho & 0.06 & Preferred \\
\hline 4 & Drepanostachyum khasianum & Poaceae & Deu Ningalo & 0.04 & Preferred \\
\hline 5 & Jasminum humile & Oleaceae & Kali Sanguto & 0.04 & Preferred \\
\hline 6 & Rubus biflorus & Rosaceae & Aainselu & 0.03 & Preferred \\
\hline 7 & Cotoneaster microphyllus & Rosaceae & Ghungyaru & 0.02 & Preferred \\
\hline 8 & Cotoneaster affinis & Rosaceae & Raisya & 0.01 & Preferred \\
\hline 9 & Ribes himalense & Grossulariaceae & Pangro & 0 & Randomly Used \\
\hline 10 & Viburnum cotinifolium & Sambucaceae & Banchhudo & 0 & Randomly Used \\
\hline 11 & Philadelphus tomentosus & Hydrangeaceae & NA & -0.16 & Avoided \\
\hline 12 & Sabia campanulata & Sabiaceae & NA & -0.25 & Avoided \\
\hline 13 & Berberis aristata & Berberidaceae & Chutto & -0.27 & Avoided \\
\hline 14 & Unidentified & NA & Pitaielo & -0.28 & Avoided \\
\hline 15 & Unidentified & NA & Chellelya & -0.3 & Avoided \\
\hline 16 & Rosa macrophylla & Rosaceae & Kuiyeshi & -0.37 & Avoided \\
\hline 17 & Salix denticulata & Salicaceae & Baish & -0.41 & Avoided \\
\hline 18 & Prinsepia utilis & Rosaceae & Dhatenlo & -0.42 & Avoided \\
\hline 19 & Coriaria nepalensis & Coriariaceae & Machaino & -1 & Avoided \\
\hline
\end{tabular}

NA = not available.

0.27) and Galium asperifolium (IV $=0.22$ ) whereas Hemiphragma heterophyllum (IV $=-1.00)$ and Urtica dioica (IV $=-1.00$ ) were the most avoided herbaceous plant species including Artemisia dubia (IV $=-0.29)$ (Table 3).

\subsubsection{Cover}

1) Crown cover

Red panda preferred the dense coverage (IV $=0.28$ ) only. A red panda observed during the field work was also in the dense crown coverage category. All other cover classes found in the area i.e. sparse (IV $=-1.00)$, open (IV $=-0.50$ ) and moderate (IV $=-0.47$ ) were found to be avoided by the species (Figure 8). 
Table 3. Herb species according to preference by red panda.

\begin{tabular}{|c|c|c|c|c|c|}
\hline S.N. & Scientific name & Family & Local name & IV & Status \\
\hline 1 & Polygonatum cirrhifolium & Liliaceae & Khiraunle & 0.32 & Preferred \\
\hline 2 & Fragaria nubicola & Rosaceae & Bhui Kafal & 0.27 & Preferred \\
\hline 3 & Galium asperifolium & Rubiaceae & chittu & 0.22 & Preferred \\
\hline 4 & Rumex nepalensis & Polygonaceae & Halhale & 0.16 & Preferred \\
\hline 5 & Unidentified & NA & Thatar & 0.16 & preferred \\
\hline 6 & Ajuga lupulina & Labiateae & Bhugelo & 0.07 & Preferred \\
\hline 7 & Dryopteris sp. & Dryopteridaceae & Wunniu & 0.07 & Preferred \\
\hline 8 & Asparagus filicinus & Liliaceae & Kudilo & 0.02 & Preferred \\
\hline 9 & Thalictrum foliolosum & Ranunculaceae & Bansuli & -0.03 & Avoided \\
\hline 10 & Cirsium verutum & Compositae & Thakailo & -0.05 & Avoided \\
\hline 11 & Pleurospermum dentatum & Umbelliferae & Gunaino & -0.09 & Avoided \\
\hline 12 & Girardinia diversifolia & Urticaceae & Allo/Thulo Sisnu & -0.09 & Avoided \\
\hline 13 & Unidentified & NA & Bina & -0.14 & Avoided \\
\hline 14 & Lycopodium clavatum & Lycopodiaceae & Ralo & -0.23 & Avoided \\
\hline 15 & Artemisia dubia & Compositae & Titepati & -0.29 & Avoided \\
\hline 16 & Hemiphragma heterophyllum & Scrophulariaceae & Nas Jhar & -1 & Avoided \\
\hline 17 & Urtica dioica & Urticaceae & Sisnu & -1 & Avoided \\
\hline
\end{tabular}

NA = not available.

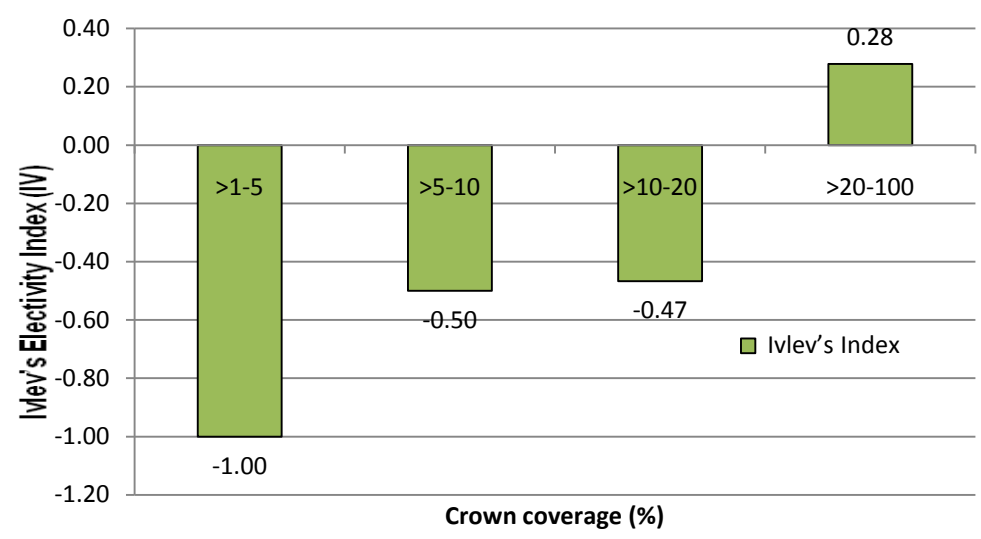

Figure 8. Percentage of crown coverage preference by red panda.

2) Ground cover

Red panda highly preferred $31 \%$ - 50\% ground cover (IV = 0.09) followed by $51 \%-100 \%$ ground cover $(\mathrm{IV}=$ 0.05). A red panda observed during the field work was in the $31 \%-50 \%$ ground coverage category. Red panda completely avoided $\leq 10 \%$ ground cover (IV $=-1.00$ ) and moderately avoided $11 \%-30 \%$ cover class (IV = -0.20 ) (Figure 9).

\section{Discussion}

The occurrence of red panda was found only between 2800 and $3300 \mathrm{~m}$ elevation in the study area, whereas it was found between 3000 and $4000 \mathrm{~m}$ in LNP [3], between 2800 and $3650 \mathrm{~m}$ in KCA [12], between 2800 and $3400 \mathrm{~m}$ in SNP [14], between 2600 and $3000 \mathrm{~m}$ in Jamuna and Mabu VDC of Illam district in Eastern Nepal [21], between 3000 and $3600 \mathrm{~m}$ in DHR [16], between 3117 and $3591 \mathrm{~m}$ in RNP [19] and between 2600 and 


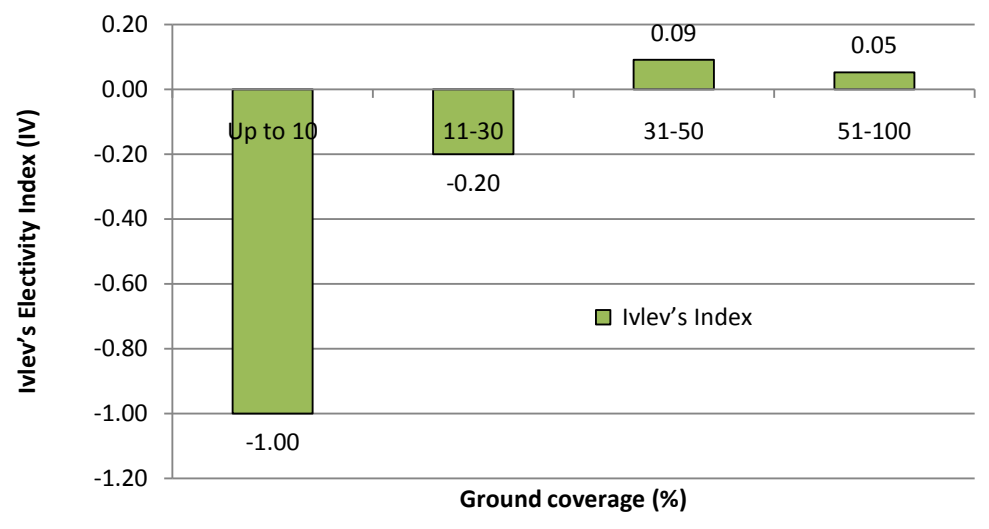

Figure 9. Percentage of ground coverage preference by red panda.

$3600 \mathrm{~m}$ in the Singhalila National Park Darjeeling, India [7]. Roberts and Gittleman [1] mentioned red panda's distribution ranging from 2200 to 4800 in the Himalayas. The Tyakot forest of Malikathata VDC possessed highest percentage (50\%) of sign evidences followed by Imilchadamar and Bahirepatan of Tamti and Ghodemahadev VDC respectively. This might be due to the less human and livestock disturbances in the Tyakot forest.

One adult red panda was sighted in Tyakot forest $\left(29^{\circ} 08^{\prime} 36.7^{\prime \prime} \mathrm{N}, 82^{\circ} 02^{\prime} 04.0^{\prime \prime} \mathrm{E} ; 2894 \mathrm{~m}\right)$ on southwest facing slope; similar observations were also made by Sharma and Belant [16] and Sharma [19]. Sighting of single red panda in the Tyakot forest (21 $1^{\text {st }}$ May 2013) might be due to the post mating period as mating season starts from middle of January and ends to early March [1] and red pandas are solitary outside their mating period [29].

Yonzon [32] mentioned that the single pellet group consisted several pellets. Karki [10] found single dropping of red panda consisted of 10 pellets on average. However, average number of pellets per pellet group was 12 in the present study. The sign encounter rate was considered as the tool for quantifying the abundance by different researchers. This study found average red panda sign encounter rate as 1.04 per hour which is comparable to that reported by Pradhan et al. [7] in term of number of sign encountered per 100 hours. They recorded sign encounter rate in Singhalila range; the highest sign encounter rate is $105.06 \pm 53.59$ (2800 - $3100 \mathrm{~m})$ followed by $20.31 \pm$ $10.05(2600-2800 \mathrm{~m})$ and $85.00 \pm 42.00(3100-3600 \mathrm{~m})$ per 100 hours.

Red pandas are known to be habitat specialists, maintain a small home range, and are restricted to small pockets of microhabitat [3]. In this study, red panda were found to be distributed between 2800 and $3000 \mathrm{~m}$ elevation with the frequency of the pellet groups increasing markedly from 2800 to $3000 \mathrm{~m}$ and then declining gently towards the higher elevation. No evidence of red panda's presence was observed at the elevations $<2800$ $\mathrm{m}$ and $>3300 \mathrm{~m}$. Red panda preferred the altitudinal range of $2800-3300 \mathrm{~m}$ (Figure 3) with higher preference to the narrow elevation range of $3000-3100 \mathrm{~m}(\mathrm{IV}=0.20)$. In comparison, Pradhan et al. [7] found red panda distributed in the entire study area in Singhalila National Park with the mean altitudinal range of 2600 - 3600 m; however distribution was relatively more abundant within an altitudinal range of $2800-3600 \mathrm{~m}$. Karki [10] found that the red pandas were mostly distributed within the altitudinal range of 3000 - $3200 \mathrm{~m}$ of CholangpatiDokachet Area, Langtang National Park. However, contrary to this, Sharma and Belant [16] found that, the most preferable elevation of the red panda was $3500 \mathrm{~m}$ and no evidences of red pandas were observed at the elevation above $3730 \mathrm{~m}$. Distribution of the pellet groups within the narrow elevation range found in the present study was possibly due to the availability of habitat requirements, which is supported by the findings of Sharma and Belant [16] i.e. distribution of pellet groups appeared positively associated with the abundance of bamboos Arundinaria spp. and availability of water sources.

Red panda mostly preferred the steep slopes followed by escarpments/cliffs. Most of the pellet groups were recorded in the steep slope (IV $=0.14,37.50 \%$ ) whereas least in the very gentle slope (IV $=-1.00,3.57 \%)$. This might be to avoid the competition with the livestock; the very gentle and gentle slopes were mostly used by livestock for grazing in the study area. The signs of red panda presence were recorded mostly in the southwest facing slopes (44.64\%) followed by northwest facing slopes (26.79\%) indicating that southwest and northwest facing slopes are preferred slope of red panda. This might be due to the presence of habitat requisites specifically food availability for red panda. Our findings are similar to those of Karki [10], who recorded that red panda mostly preferred northwest facing slopes (64\%) followed by northeast (29\%) while the most preferred slope was 
$37^{\circ}$. Red Panda Network (RPN)-Nepal [33] found frequency of red panda sign encounter in Sacred Himalayan Landscape (SHL) of Nepal as higher between $30^{\circ}$ to $70^{\circ}$ slopes accounting for almost $90 \%$ of sign encountered with higher preference to steep forested terrain, with high moisture which usually observed on the north and west facing slopes.

The study in Langtang National Park, Nepal by Yonzon and Hunter [29] indicated that proximity to water may be the important habitat requirement because $90 \%$ of the droppings were found within $100 \mathrm{~m}$ of the nearest water sources. Similarly, Pradhan et al. [7] mentioned the water availability as the habitat requisite for red panda, as $79 \%$ of the evidences of the red panda were at the distance $0-100 \mathrm{~m}$ from water bodies which further reflected the importance of water in its preferred habitat sites. This is supported by the observation made by Kandel [15] and Dorji et al. [8]. Red panda mostly preferred the distance less than or equal to $100 \mathrm{~m}(\mathrm{IV}=0.13)$, moderately preferred the distance of (101 - 200) m whereas mostly avoided the distance greater than $200 \mathrm{~m}$ from the water sources in the present study area.

As high as $39 \%$ of pellet groups were found on fallen logs followed by forest floor and uprooted tree with $25 \%$ each and $11 \%$ on the rock cliff. In contrary to this, Pradhan et al. [7] found that, during pre-monsoon (MarchMay), trees (70\%) were the most preferred defecation substrate for the species, this is supported by the findings of Williams [21] and Kandel [15]. Most signs observed during the study were old and most of the evidences were found in the fallen logs, forest floors and uprooted trees, probably the substrates were used during post monsoon and winter seasons. Similarly, Pradhan et al. [7] suggested that the higher use of forest floor during monsoon was probably because the red panda was seeking bamboo shoots on the forest floors. Besides, pellet groups mostly found on the forest floor, paths on ridges and slopes, could be a mode of communication between the species as winter happens to be its mating season.

The habitat of red panda is associated with the occurrence of subtropical and temperate forests with exceptional case in tropical forest of Meghalaya in India [6]. Based on the vegetation classification given by Shrestha [34], the habitat of red panda in this study area falls within the temperate and subalpine forests.

The preferred habitat of red panda in Dhorpatan Hunting Reserve was dominated by Abies spectabilis, Rhododendron campanulatum, Betula utilis, Juniperus indica and Arundinaria spp. [15] [16]. In the present study area habitat of red panda was dominated by Quercus semecarpifolia, Abies spectabilis, Betula utilis and Acer spp. Furthermore, out of nine species recorded in the study area, red panda preferred Acer spp., Betula utilis and Quercus semecarpifolia where as it randomly used Abies spectabilis and avoided Tsuga dumosa, Juglans regia, Picea smithiana and Pinus wallichiana. The present study was supported by the study conducted by Panthi et al. [17] who reported that the red panda showed higher preference to Acer caesium, Abies spectabilis and Quercus semecarpifolia. The preferred tree species in the study area might be used by red panda for nesting, sleeping and sheltering.

Out of 19 shrubs recorded in the study area, red panda preferred only eight species. Red panda highly preferred Elaeagnus parvifolia and Drepanostachyum spp. Red panda was found eating the leaves of both species of bamboo, Arundinaria maling and A. aristata predominantly present as understory in Singhalila National Park [7], similar observation were also made by Yonzon and Hunter [9], Karki [10], Thapa [11] in Langtang National Park, Kandel [15], Sharma and Belant [16], Panthi et al. [17] in Dhorpatan Hunting Reserve, Sharma [19] in Rara National Park and Mallick [35] in Neora Valley National Park India. Similarly, three species of bamboo, Drepanostachyum falcatum, D. intermedium and D. khasianum were found most preferred and present as understory in the habitat of red panda in Jumla. Eight herbaceous plants including Polygonatum cirrhifolium, Fragaria nubicola, Galium asperifolium were found to be preferred by red panda. The local villagers mentioned that the study area as most potential area for the medicinal herbs and their exploitation is high.

Canopy coverage is the important habitat component in the red panda habitat and it prefers forest with greater canopy cover [7] [21]. In the study area, red panda preferred dense crown coverage (>20\% - 100\%). It was probably due to crown coverage might be used for hiding, resting and thermoregulation; for the protection and maintaining body temperature within narrow tolerable limit. Panthi [36] also found that red panda mostly preferred the crown coverage of $51 \%$ - 75\% (IV $=0.21$ ) followed by $76 \%$ - 100\% (IV = 0.08).

Red panda preferred $\geq 31 \%$ - $100 \%$ ground coverage, however avoided the ground coverage $\leq 30 \%$, probably it used dense ground cover for hiding and movements. Panthi [36] mentioned that red panda preferred the moderate ground cover of $(26 \%-50 \%)$ while avoided low ground cover $(\leq 25 \%)$ followed by high ground cover $(\geq 51 \%-100 \%)$.

Although red panda is a carnivore, it is used to pure herbivore diet, primarily consisting of leaves and shoots 
of bamboo species. Its other dietary includes berries, fruits, mushrooms, acorns and lichens [7] [9]. In addition, the annual diet of red panda comprises leaves of ringal bamboo (Jhapra and Raate) (68.4\%), followed by ringal shoots (14.6\%), fruits of Sorbus cuspidata (9.23\%), berries of Sorbus microphylla (6.15\%) and mushroom (1.6\%) [7]. The villagers and herders of the study area mentioned that red panda mainly feeds on leaves and shoot of Drepanostachyum spp. (Jurmutho, Malingo and Deu Ningalo) and partially on fruits of Rubus biflorus (Aainselu), Cotoneaster microphyllus (Ghungyaru), Berberis aristata (Chutto), Elaeagnus parvifolia (Gunyalo) and Fragaria nubicola (Bhui Kafal). Captive red panda were observed to eat birds and have shown particular interest in sweetened food and readily consumed meat [1], while the herders of study area mentioned that red panda killed and devoured the newly born young of goat and sheep, but this is doubtful and need further verification.

\section{Conclusion}

The study revealed the presence of red panda in the Bahirepatan, Tyakot and Imilchadamar forests of Godhemahadev, Malikathata and Tamti VDCs respectively. The evidences (pellet groups) of red panda found distributed from the elevation of $2880 \mathrm{~m}$ to $3244 \mathrm{~m}$.

Red panda mostly preferred the habitat in the elevation range from 2900 to $3000 \mathrm{~m}$ with southwest facing steep slopes $\left(36^{\circ}-45^{\circ}\right)$, associated with water availability (at distance $\leq 100 \mathrm{~m}$ ). In addition, red panda mostly preferred the tree species of Acer spp., Betula utilis and Quercus semecarpifolia, shrub species of Elaeagnus parvifolia, Drepanostachyum spp. and Jasminum humile, and herbaceous of Polygonatum cirrhifolium, Fragaria nubicola and Galium asperifolium. The red panda preferred the habitat with dense crown coverage ( $>20 \%$ $100 \%$ ) and 31\% - 50\% ground cover. Moreover, fallen logs (39\%) were mostly preferred to use by red panda for defecation.

\section{Acknowledgements}

We are highly grateful to Red Panda Network (RPN) for financial and equipment support to conduct this study. We are obliged to College of Applied Sciences-Nepal (CAS), Nepal government's Department of National Parks and Wildlife Conservation (DNPWC), Department of Forest (DoF) and District Forest Office (DFO), Jumla for permitting to carry out this study in Jumla district. We are thankful to Mr. Badri Baral for his tireless effort and co-operation throughout the field survey, and to the field guide Mr. Bir B. Rawat, Mr. Padam Budha and Mr. Rabi Thapa and all the local people, respondents, herders and hotel owners for their support and friendly behavior during the field survey.

\section{References}

[1] Robert, M.S. and Gittleman, J.L. (1984) Ailurus fulgens. Mammalian Species, No. 222, 1-8. http://dx.doi.org/10.2307/3503840

[2] Glatston, A.R. (1994) Status Survey and Conservation Action Plan for Procyonids and Ailurids. IUCN/SSC Mustelid, Viverrid, and Procyonid Specialist Group, IUCN, Gland, Switzerland.

[3] Yonzon, P.B., Yonzon, P., Chaudhary, C. and Vaidya, V. (1997) Status of the Red Panda in the Himalayas. A Resources Nepal Project with Support from the Metropolitan Toronto Zoo, Resources Nepal, Kathmandu, Nepal.

[4] Wei, F., Feng, Z., Wang, Z. and Hu, J. (1999) Current Distribution, Status and Conservation of Wild Red Pandas Ailurus fulgens in China. Biological Conservation, 89, 285-291. http://dx.doi.org/10.1016/S0006-3207(98)00156-6

[5] Chakraborty, T. (1999) Himalayan Heritage: The Endangered Red Panda in Himalayan Paryavaran. The Journal of Environmental Protection Society, 6, 129-132.

[6] Choudhury, A. (2001) An Overview of the Status and Conservation of the Red Panda Ailurus fulgens in India, with Reference to Its Global Status. Oryx, 35, 250-259. http://dx.doi.org/10.1017/S0030605300031926

[7] Pradhan, S., Saha, G.K. and Khan, J.A. (2001) Ecology of the Red Panda Ailurus fulgens in the Singhalila National Park, Darjeeling, India. Biological Conservation, 98, 11-28. http://dx.doi.org/10.1016/S0006-3207(00)00079-3

[8] Dorji, S., Vernes, K. and Rajaratnam, R. (2011) Habitat Correlates of the Red Panda in the Temperate Forests of Bhutan. PLoS One, 6, 1-11. http://dx.doi.org/10.1371/journal.pone.0026483

[9] Yonzon, P.B. and Hunter, M.L (1989) Ecological Study of the Red Panda in the Nepal-Himalayas. In: Glatson, A.R., Ed., Red Panda Biology, Academic Publication, The Hauge, Netherlands, 1-8. 
[10] Karki, K. (2009) Habitat and Feeding Behavior of Red Pand (Ailurus fulgens) in Cholangpati-Dokachet Area, Langtang National Park, Nepal. M.Sc. Thesis, Central Department of Zoology, Tribhuvan University, Kathmandu.

[11] Thapa, A. (2010) An Analysis of Food Habitats and Conservation of Red Panda (Ailurus fulgens, Cuvier 1825) in Langtang National Park, Nepal. M.Sc. Thesis, Central Department of Zoology, Tribhuvan University, Kathmandu.

[12] Mahato, N.K. (2003) Status of Red Panda, Ailurus fulgens (Cuvier, 1825) in the Kanchenjunga Conservation Area, Nepal. A Project Paper, Submitted in the Partial Fulfillment of the Requirement for the Degree of Bachelor of Science in Forestry, Tribhuvan University, Institute of Forestry, Pokhara Campus, Nepal.

[13] Suwal, R.N. and Verheugt, W.J.M. (1995) Enumeration of Mammals of Nepal. Biodiversity Profile Project Technical Publication No. 6, Department of National Parks and Wildlife Conservation, Ministry of Forest and Soil Conservation, His Majesty of Government of Nepal, Kathmandu.

[14] Mahato, N.K. (2004) Baseline Survey of Red Panda Aliurus fulgens Status in the Buffer Zone of Sagarmatha National Park. A Report, Submitted to WWF Nepal Program, Kathamandu.

[15] Kandel, R.N. (2008) Distribution and Conservation Status of Red Panda (Ailurus fulgens) in Dhorpatan Hunting Reserve, Nepal. M.Sc. Thesis, Central Department of Zoology, Tribhuvan University, Kathmandu.

[16] Sharma, H.P. and Belant, J.L. (2009) Distribution and Observations of Red Pandas Ailurus fulgens fulgens in Dhorpatan Hunting Reserve, Nepal. Small Carnivore Conservation, 40, 33-35.

[17] Panthi, S., Aryal, A., Raubenheimer, D., Lord, J. and Adhikari, B. (2012) Summer Diet and Habitat Ecology of Red Panda (Ailurus fulgens fulgens) in Dhopatan Hunting Reserve, Nepal. Zoological Studies, 51, 701-709.

[18] Panthi, S., Dhakal, M., Thagunna, S.S. and Thapa, B.B. (2014) Status of Wetland in Dhorpatan Hunting Reserve, Nepal. Open Journal of Ecology, 4, 245-252.

[19] Sharma, H.P. (2012) Exploration and Diet Analysis of Red Panda (Ailurus fulgens) for Its Conservation in Rara National Park, Nepal. A Report, The Rufford Small Grants Foundation, London.

[20] Thapa, A. (2013) Conservation Status of Red Panda (Ailurus fulgens) in Gaurishankar Conservation Area, Central Nepal. A Report, The Rufford Small Grants Foundation, London.

[21] Williams, B.H. (2004) The Status of the Red Panda in Jamuna and Mabu Villages of Eastern Nepal. M.Sc. Thesis, The Faculty of the Department of Environmental Studies, San Jose State University, San Jose.

[22] Mahato, N.K., Kandel, K. and Shakya, S. (2011) A Long-Term Community-Based Monitoring and Conservation Program for Red Panda in Unprotected Forests of Eastern Nepal. Tiger Paper, 38, 1-10.

[23] Kandel, K. (2011) Community Based Red Panda Study in Bhotkhola Area, Sankhuwasabha District, Nepal. A Report, The East Foundation (TEF), Sankhuwasabha.

[24] Paudel, K. (2009) Status and Distribution of Red Panda (Ailurus fulgens) in Manang District, Nepal. A Project Paper Submitted in the Partial Fulfillment of the Requirement for the Degree of Bachelor of Science in Forestry, Tribhuvan University, Institute of Forestry, Pokhara Campus, Nepal.

[25] Dangol, B. (2014) Habitat and Distribution Analysis of Red Panda (Ailurus fulgens) in Ranchuli VDC, Kalikot, Nepal. A Report, Red Panda Network (RPN), Baluwatar, Kathmandu.

[26] Baral, B. (2014) Baseline Study of Red Panda (Ailurus fulgens fulgens, Cuvier, 1825) in Jajarkot District, Western Nepal. A Report Submitted to Red Panda Network (RPN), Baluwatar, Kathmandu.

[27] DDC-Jumla (2007) A District Transportation Master Plan (DTMP), Jumla District, Mid-Western Nepal. A Master Plan Prepared by Ministry of Local Development, Government of Nepal, Kathmandu, 1, 1-13.

[28] Ivelv, V.S. (1961) Experimental Ecology of the Feeding of Fishes. Yale University Press, New Haven.

[29] Yonzon, P.B. and Hunter, M.L. (1991) Conservation of Red Panda Ailurus fulgens. Biological Conservation, 57, 1-11. http://dx.doi.org/10.1016/0006-3207(91)90104-H

[30] Cottam, G. (1949) The Phytosociology of an Oak Wood in Southwestern Wisconsin. Ecology, 30, 271-287. http://dx.doi.org/10.2307/1932609

[31] Anbalagan, R. and Singh, B. (2001) Landslide Hazard and Risk Mapping in the Himalaya. A Paper in Landslide Hazard Mitigation in the Hindu Kush Himalayas, International Center for Integrated Mountain Development, Kathmandu, 163-188.

[32] Yonzon, P.B. (1989) Ecology and Conservation of Red Panda. Unpublished Ph.D. Thesis, University of Maine, Orono.

[33] RPN-Nepal (2010) Study on Ecology, Behavior and Conservation of Red Panda in the Sacred Himalayan Landscape of Nepal (SHL). A Comprehensive Report Submitted to World Wildlife Fund-Nepal (WWF-Nepal) Program, Kathmandu.

[34] Shrestha, T.B. (1982) Ecology and Vegetation of North-West Nepal, Silver Jubilee Publication Series: 23. Royal Nepal Academy, Kathmandu. 
[35] Mallick, J.K. (2010) Status of Red Panda Ailurus fulgens in Neora Valley National Park, Darjeeling District, West Bengal, India. Small Carnivore Conservation, 43, 30-36.

[36] Panthi, S. (2011) Feeding Ecology, Habitat Preference and Distribution of the Red Panda (Ailurus fulgens fulgens) in Dhorpatan Hunting Reserve, Nepal. A Project Paper Submitted in the Partial Fulfillment of the Requirement for the Degree of Bachelor of Science in Forestry, Tribhuvan University, Institute of Forestry, Pokhara Campus, Nepal. 
Scientific Research Publishing (SCIRP) is one of the largest Open Access journal publishers. It is currently publishing more than 200 open access, online, peer-reviewed journals covering a wide range of academic disciplines. SCIRP serves the worldwide academic communities and contributes to the progress and application of science with its publication.

Other selected journals from SCIRP are listed as below. Submit your manuscript to us via either submit@scirp.org or Online Submission Portal.
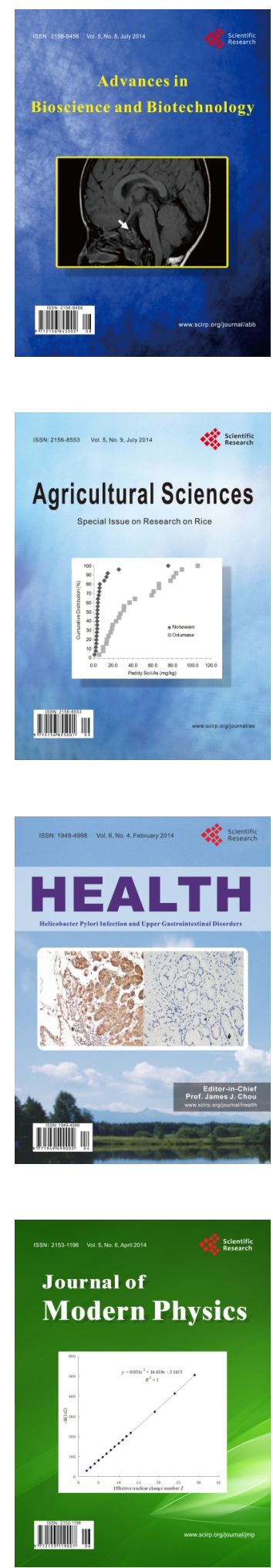
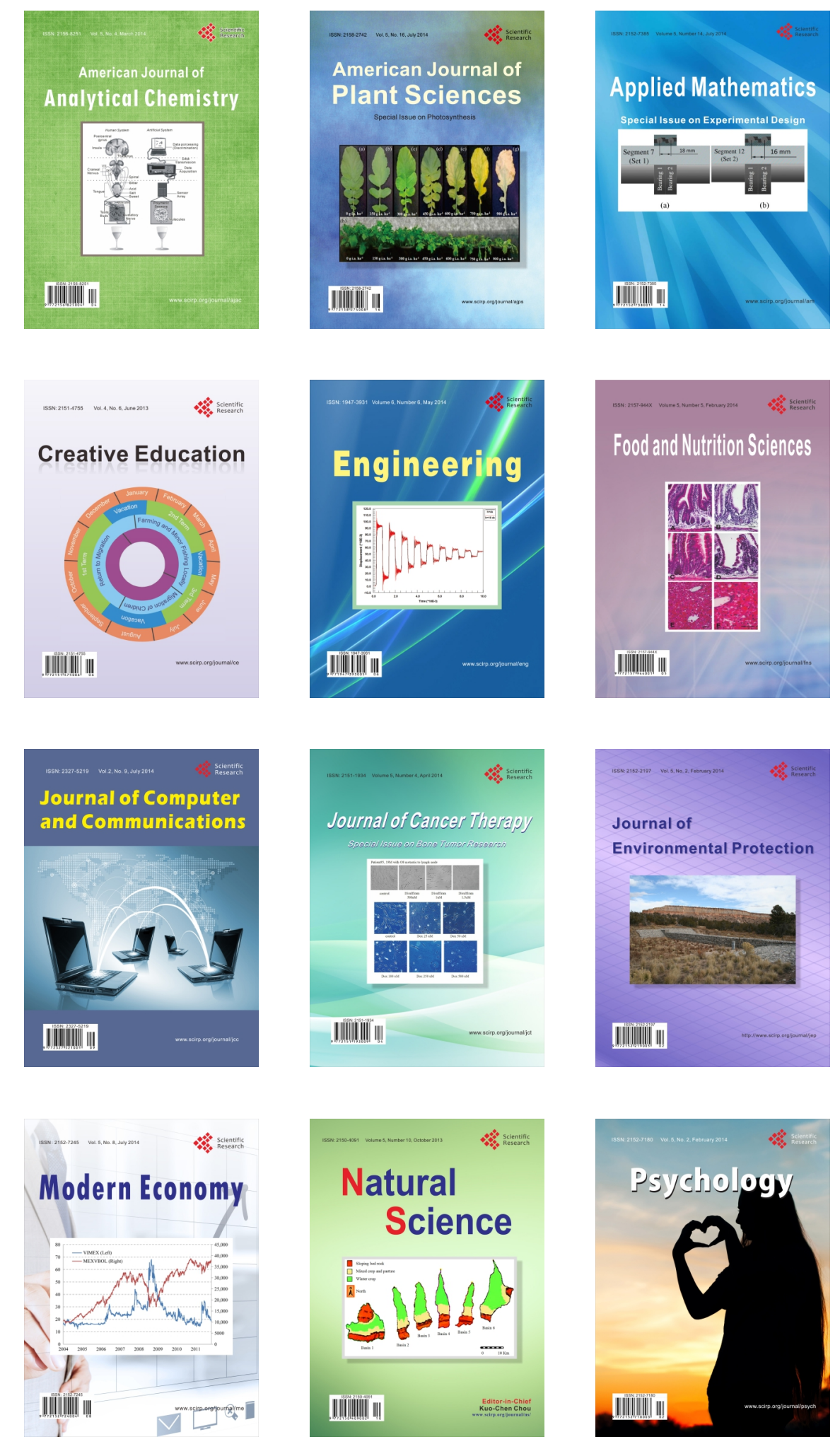